\title{
Irrational risk-taking of professionals? The relationship between risk exposures and previous profits
}

\author{
Edina Berlinger ${ }^{1} \cdot$ Barbara Dömötör $^{1}$ (D) Balázs Árpád Szűcs ${ }^{1}$
}

Accepted: 24 May 2021 / Published online: 11 June 2021

(c) The Author(s) 2021

\begin{abstract}
The risk attitude of investors is a key factor determining financial asset prices and market trends. Changes in risk attitude may be due to the interference of macro-level (business cycle) and micro-level (individual experience) effects. We investigate the impact of individual experience on the subsequent risk-taking attitude of professionals via the analysis of the trading activity of 351 non-financial firms and (non-bank) financial institutions (insurance companies, financial intermediaries, etc.) covering 57,039 FX forward transactions in a highly volatile period between January 2008 and November 2012. Panel regressions for all firms and institutions do not show significant behavioral patterns. When investigating each client separately, however, we find that $39.7 \%$ of the clients having enough transactions to analyze statistically tend to increase their risk exposure irrationally after large gains or losses which can be the manifestation of the break-even and house-money effects well-documented in the literature for non-professionals. This irrational behavior may destroy value, so both market players and regulators should pay attention to monitor and control it.
\end{abstract}

Keywords Corporate risk management $\cdot$ Behavioral finance $\cdot$ Individual experience . Break-even effect $\cdot$ House-money effect

JEL Classification G02 · G11

Barbara Dömötör

barbara.domotor@uni-corvinus.hu

Edina Berlinger

edina.berlinger@uni-corvinus.hu

Balázs Árpád Szúcs

balazsarpad.szucs@uni-corvinus.hu

1 Department of Finance, Corvinus University of Budapest, Fővám Square 8, Budapest 1093, Hungary 


\section{Introduction and literature review}

The risk attitude of economic players affects risk premia, investment decisions, and asset prices (Benchimol 2014). This is especially true in the case of highrisk investments like innovative start-ups and emerging markets. Risk attitude is an important factor even in developed industries and countries as it may become endogenous and path-dependent, and positive feedback effects may lead to bubbles and increased systemic risk.

Rational models of decision making assume that players are maximizing their utility function which is stable over time. Utility is usually a concave function of wealth, which implies risk-averse players. According to a large body of empirical and experimental literature, people tend to risk more dollars as they get richer, so their absolute risk aversion is decreasing in wealth (Tversky and Kahneman 1992). This is consistent with CRRA (constant relative risk aversion) utility functions, too, which are the most popular in economic literature (Arrow 1965; Mehra and Prescott 1985; Herings and Kubler 2007), implying that people keep a constant percentage of their portfolio in risky assets independently of their actual level of wealth. Therefore, in rational models with a CRRA utility function (in a stable environment), if the investor realizes a positive profit, his wealth increases, the percentage of risky assets remains constant, but the absolute value of the risky assets increases, so there is a positive relationship between previous profits and the subsequent absolute risk exposure. (We use the term ,profit" as a signed number, a negative profit means a loss.)

Contrary to this, Goetzmann et al. (2007) demonstrated that rational players may be motivated to decrease (increase) their risk exposure after large random positive (negative) profits. They do so when they try to manipulate classical performance measures which build on the concept of risk-adjusted expected return (e.g., Sharpe-ratio). So, we have a rational explanation for the negative relationship between previous profits and risk-taking, too.

Beyond rationality, Minsky (1986) described a procyclical behavior of the investors implying a strong positive relationship between profits and risk-taking. According to the financial instability hypothesis, people tend to take increasingly risky positions in a booming market, and when the bubble bursts, risk aversion increases dramatically, and market players start to deleverage their positions intensively. This Minsky-effect has three components: (i) investors remember less those events that happened long ago (recency effect), (ii) investors expect the trend to continue (momentum trading), (iii) previous positive profits increase risktaking (experience-based risk-taking attitude).

Cohn et al. (2015) analyzed the behavior of financial market professionals on a hypothetical equity market with the help of a laboratory experiment and found a strong Minsky-effect: in a boom scenario, risk appetite increased while in a bust scenario, it decreased significantly. This effect helps to understand the building up and down of asset bubbles which contributes to the high volatility of financial markets. Guiso et al. (2018) strengthened this by surveying the clients of an Italian bank and investigating their portfolio data. They found that after the 
crisis of 2008, clients heavily divested stocks, which could not be explained on a rational basis, these decisions were rather emotionally driven. Mengel et al. (2016) designed an experiment to analyze time-varying risk appetite at a microlevel focusing on the effects of individual experience. Participants of the experiment could choose between a risk-free investment and a lottery. It turned out that large uncertainty experienced in the past led to a decreased risk appetite. This result can provide a micro-level explanation for the Minsky-effect.

The prospect theory supported by a large amount of psychological experiments states that people evaluate the outcome of risky investments relative to a reference point which is not stable over time, their value function is concave for positive profits and convex for losses; moreover, they use subjective probabilities (Tversky and Kahneman 1979). These findings cannot be reconciled with utility maximization and result in a special fourfold pattern of risk-taking (Tversky and Kahneman 1992). People are risk-averse when they expect to win with high probability (equity investments) or to loose with low probabilities (insurance), and they are risk seeking when they expect to win with low probability (lottery) or to loose with high probability (break-even effect).

Post et al. (2008) analyzed the database of a TV show (Deal or no deal?) and found that people tended to risk more (less) after profits of large (small) absolute value. These findings were strengthened by laboratory experiments, as well. Post et al. (2008) concluded that people had difficulties to adapt to new situations, their reference point is sticky. After losing a lot, players tried to avoid loss realization at any cost, so they took irrationally large risk just to give themselves a chance to get back to the initial (zero-loss) position (break-even effect); and conversely, after winning a lot, they did not consider the gain as real, they thought it was still the money of the casino (the house) and risked it more easily in the spirit of ,easy-come-easygo" (house-money effect). Clearly, both break-even and house-money effects can be attributed to mental accounting problems. Note that an increasing risk appetite following large positive profits can be attributed to other behavioral effects, as well, for example to the confirmation bias (searching for, interpreting, favoring, and recalling information in a way that confirms or supports one's prior beliefs or values) or to overconfidence (when a person's subjective confidence in his or her judgments is greater than the objective value of those judgments).

Interestingly, also professional traders seem to exhibit these irrational behavioral effects. Coval and Shumway (2005), for example, observed a strong intraday breakeven effect on the US T-bonds' futures market of the Chicago Board of Trade. They analyzed all transactions on the traders' own account in 1998 and found that traders suffering loss in the morning session were $16 \%$ more likely to take above-the-average risk in the afternoon. This effect did not prevail on a longer term, so the gains and losses had no further effect on the next day's behavior. Also, Faulkender (2005) and Brown et al. (2006) showed that the hedging activity of corporations is dominated by behavioral effects, and it is characterized rather by myopic speculation than rational, text-book-style risk management.

In this paper, we investigate behavioral effects on risk-taking similarly to Post et al. (2008) but we focus on 351 non-financial firms and non-bank financial institutions (insurance companies, financial intermediaries, etc.), being the clients of the 
Hungarian branch of ING Bank. We analyze their trading activity on the FX forward market. We can disregard the effects of the general market sentiment and can focus on the micro-level experience with previous profits because traders on the forward market can have both long and short positions, and we control for the general macro trends. However, our investment horizon is much longer than that of Post et al. (2008) or Coval and Schumway (2005) who investigated intraday behavioral patterns, whereas we calculate profits and exposures on a monthly basis and run panel regression models with time and firm fixed effects. We find no general behavioral patterns characterizing the whole sample, which can be explained by the longer time horizon and/or the rationality of most of the professional traders.

In the next step, we analyze the behavior of the clients one by one on a daily basis. Profits are calculated as the exponentially weighted average of the previous year's daily profits (giving more weight to the recent experience), and the risk exposure is the absolute value of the aggregate (gross or net) open positions at the end of the day denominated in Hungarian forint. We examine the relationship between previous profits (explanatory variable) and the subsequent risk exposure (dependent variable) with the help of multivariate OLS regression for each player where the control variable is the average FX position of the given player which is a proxy for its hedging need. Regressions are estimated separately for negative and positive profits. Regression coefficients are significant neither for negative nor for positive profits in the case of $48.2 \%$ of the clients. For $36.1 \%$ only one side is significant, and coefficients are significant for both sides only for $15.7 \%$ of the clients. However, when both sides are significant, a V-shape is dominant for $69.2 \%$ of these clients while the frequency of the other three possible shapes $(\wedge, / /, \backslash \backslash)$ altogether is only $30.8 \%$.

Thus, the V-shape is a dominant pattern, which is consistent with the findings of Post et al. (2008) as it reflects that risk appetite increases after profits of large absolute value (break-even and house-money effects). Clearly, a V-shape cannot be explained by rational decision making or the Minsky-effect, because these would imply a monotonic relationship between profits and risk-taking. It is also notable that when only one leg is significant, then it is a half V-shape in $80.0 \%$ of the cases: a negative coefficient on the negative side $(53.3 \%)$ or a positive coefficient on the positive side (26.7\%), which again can be the sign of the break-even and the housemoney effects, respectively. All in all, $39.7 \%$ of the clients show a V-shape or a half V-shape pattern, which can be due to behavioral effects.

In "Data" section, we describe the database and the methods. In "General behavioral patterns" and "Client-level behavioral patterns" sections, general and clientlevel behavioral patterns are investigated, respectively. Finally, in "Conclusions" section, we derive conclusions.

\section{Data}

We accessed a comprehensive database of all FX transactions of corporate and institutional (non-bank) clients of the Hungarian branch of ING Bank N. V. The database contains all FX-deals except the interbank transactions. The bank had 
Table 1 FX transaction numbers by year and client type

\begin{tabular}{|c|c|c|c|c|c|c|c|}
\hline & & 2008 & 2009 & 2010 & 2011 & 2012 & Sum \\
\hline $\begin{array}{l}\text { Non- } \\
\text { financial } \\
\text { corpora- } \\
\text { tions }\end{array}$ & & 4792 & 8221 & 8366 & 9354 & 7975 & 38,708 \\
\hline \multirow{8}{*}{$\begin{array}{l}\text { Financial } \\
\text { institu- } \\
\text { tions } \\
\text { (without } \\
\text { banks) }\end{array}$} & & 8627 & 7748 & 10,875 & 13,780 & 8762 & 49,792 \\
\hline & Insurance companies & 81 & 43 & 81 & 188 & 249 & 642 \\
\hline & Consolidated clients & 110 & 126 & 94 & 68 & 45 & 443 \\
\hline & Foreign financial intermediaries & 518 & 683 & 1633 & 2974 & 1763 & 7571 \\
\hline & Private insurance, health insurance & 522 & 530 & 531 & 486 & 353 & 2422 \\
\hline & Domestic financial intermediaries & 6129 & 4678 & 5889 & 7517 & 4209 & 28,422 \\
\hline & Other financial intermediaries & 1266 & 1670 & 2638 & 2540 & 2060 & 10,174 \\
\hline & Others & 1 & 18 & 9 & 7 & 83 & 118 \\
\hline Sum & & 13,419 & 15,969 & 19,241 & 23,134 & 16,737 & 88,500 \\
\hline
\end{tabular}

481 corporate and institutional (non-bank) clients between January 2, 2008 and November 3, 2012. The total number of transactions was 88,500. We received eight records for each transaction: client code (anonymous), sector code, deal date, value date, bought currency, bought amount, sold currency, and sold amount.

Around $44 \%$ of the transactions involved non-financial corporations; in the case of the remaining $56 \%$, the trading partners were (non-bank) financial institutions, see Table 1.

The number of transactions was growing in this period, peaking in 2011. Note, however, that the last year-2012 — was incomplete as data last until November.

Figure 1 shows the frequency of various currencies involved. (A transaction involves two currencies, therefore, frequencies in Fig. 1 sum up to 200\%.)

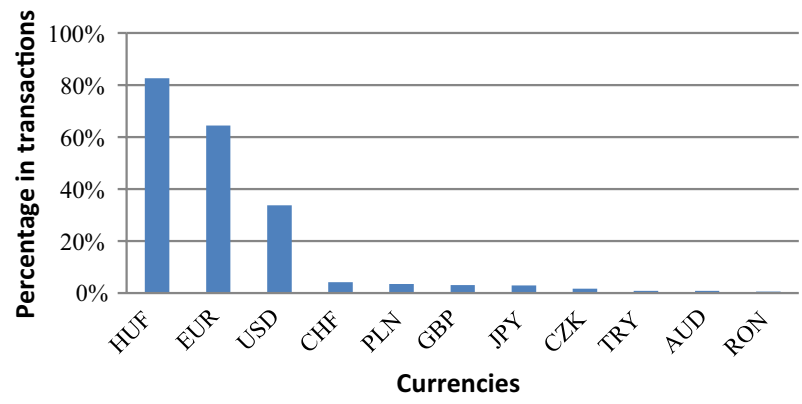

Fig. 1 Currencies involved in FX transactions 
The Hungarian forint (HUF), the euro (EUR), and the US dollar (USD) were the most frequently traded currencies, these were involved in most of the transactions.

The difference between value date and deal date is the maturity of the deal. Figure 2 depicts the frequency of the different maturities in the observed transactions.

Frequencies are ordered to the minimum of the interval on the $x$-axis. For example, almost $20 \%$ of the transactions have a less than 1-month maturity (the maturity expressed in days is 0 to 30), and most of these are spot transactions. Most deals (around 60\%) fall into the next category, their maturity is between 30 and 60 days.

After removing erroneous observations, spot deals, and non-HUF transactions, we have 57,151 transactions conducted with 351 different clients. The next step was to download daily FX rates between HUF and the other currencies from the webpage of the Hungarian National Bank (MNB). HUF rates for Slovak koruna, Hong Kong dollar, and South African rand are not available for the entire period, therefore, the 112 transactions where these currencies were involved are removed from the sample. So, finally, we get 351 clients and 57,039 transactions.

In the following, we specify how exposure and profit variables are calculated.

We do not have information about clients' other positions, just their forward positions at ING Bank, so their risk exposure cannot be measured in relative but only in absolute terms. First, we calculate the exposure $X_{i, t}$ for the $i$ th client on the $t$ th day by aggregating the HUF value of his open positions in different currencies. As it is usual in risk management, exposures can be calculated either on a net or on a gross basis:

$$
X_{i, t}=X_{i, t}^{\mathrm{net}}=\left|\sum_{j} F_{j, t} Q_{i, j, t}\right|
$$

or

$$
X_{i, t}=X_{i, t}^{\mathrm{gross}}=\sum_{j} F_{j, t}\left|Q_{i, j, t}\right|,
$$

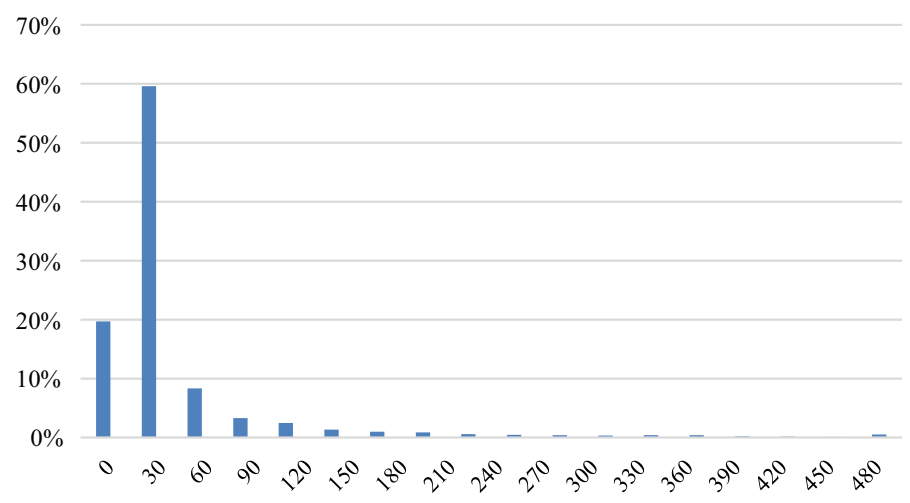

Fig. 2 Maturity of FX transactions (in days) 
where $F_{j, t}$ is the HUF spot daily mid-price of one unit of the $j$ th foreign currency downloaded from the webpage of the Hungarian National Bank (MNB) and $Q_{i, j, t}$ is the net size of the open position of the $i$ th client in the jth currency at the end of the $t$ th day expressed in units of the foreign currency (positive if long and negative if short from the client's perspective). Thus, the net and the gross exposures in (1) and (2) are non-negative numbers.

Then we determine the daily aggregate profit $\pi_{i, t}$ for each client $i$ on each day $t$ for all currencies $j$ :

$$
\pi_{i, t}=\sum_{j} Q_{i, j, t-1}\left(\frac{F_{j, t}}{F_{j, t-1}}-1\right) .
$$

By (3), for the sake of simplicity, we disregard cross-currency interest rate differences and suppose that profits come only from the change of FX rates. Note that $\pi_{i, t}$ does not equal the difference between forint values of the client exposure on consecutive days, because we adjust for expired and freshly opened positions as well.

\section{General behavioral patterns}

We assume that the clients of ING Bank, that is traders sitting in corporate or financial institutions' treasuries, take FX forward positions basically to hedge their initial FX positions coming from their core activities (export/import, service of their own clients, etc.). At the same time, however, clients may have some speculative positions as well.

Our research question is whether previous profits influence the subsequent risk exposure on the whole sample. First, to capture general patterns characterizing all clients in the sample (and to avoid too many zeros in the data table), we switch from a daily to a monthly scale:

$$
\begin{gathered}
\bar{X}_{i, m}=\frac{\sum_{t=1}^{D_{m}} X_{i, t}}{D_{m}}, \\
\bar{\pi}_{i, m}=\frac{\sum_{t=1}^{D_{m}} \pi_{i, t}}{D_{m}},
\end{gathered}
$$

where $D_{m}$ is the number of trading days in month $m$. By using the monthly average values in the regression, we can avoid insignificant results due to missing data.

The first idea would be to estimate the following panel regression model:

$$
\bar{X}_{i, m}=\alpha_{i}+\beta \bar{\pi}_{i, m-1}+\varepsilon_{i, m},
$$

where $\bar{X}_{i, m}$ is the average exposure of client $i$ in month $m$ and $\bar{\pi}_{i, m-1}$ is the average daily profit realized by client $i$ in the previous month. 
Clearly, (6) would be a misspecified model because an important variable influencing both previous profits and present exposures is omitted, namely previous exposures. The larger previous exposures were profits of larger absolute values could have been realized, and the present exposure is supposed to be larger, too. Assuming a stable business activity of the clients, previous exposures serve also as a proxy for the actual hedging need.

To investigate the relationship between exposures and previous profits, we should look back in time for several months to capture the potential long-lasting effects, so we use four lagged values of the monthly profits. According to prospect theory, it is worth to differentiate between negative and positive profits, so we also apply the four lagged variables both for positive and negative monthly profits separately. Introducing a dummy variable for December, we also control for the increased activity of the traders at the end of the year, which can be motivated by window-dressing (Lakonishok et al. 1991). Firm fixed effects $\left(\alpha_{i}\right)$ account for differences in firms' characteristics, and year dummies control for the macro trends (price movements, volatility, other macro conditions).

Explanatory variables in the panel regressions are summarized in Table 2.

So, the general form of the investigated panel regression model is specified as

$$
\bar{X}_{i, m}=\alpha_{i}+\sum_{k=1}^{4} \beta_{k} \bar{\pi}_{i, m-k}+\delta \bar{X}_{i, m-1}+\theta \mathrm{DEC}+\sum_{l=2009}^{2012} \tau_{l} \mathrm{YEAR}_{l}+\varepsilon_{i, m}
$$

Table 2 Explanatory variables of the panel regression models

\begin{tabular}{ll}
\hline Explanatory variables & Notation \\
\hline Average exposure of the previous month $(M H U F)$ & $\bar{X}_{i, m-1}$ \\
Monthly average profit lagged by 1 month $(M H U F)$ & $\bar{\pi}_{i, m-1}$ \\
Monthly average profit lagged by 2 months $(M H U F)$ & $\bar{\pi}_{i, m-2}$ \\
Monthly average profit lagged by 3 months $(M H U F)$ & $\bar{\pi}_{i, m-3}$ \\
Monthly average profit lagged by 4 months $(M H U F)$ & $\bar{\pi}_{i, m-4}$ \\
Monthly average positive profit lagged by 1 month $(M H U F)$ & $\bar{\pi}_{i, m-1}^{+}$ \\
Monthly average positive profit lagged by 2 months $(M H U F)$ & $\bar{\pi}_{i, m-2}^{+}$ \\
Monthly average positive profit lagged by 3 months $(M H U F)$ & $\bar{\pi}_{i, m-3}^{+}$ \\
Monthly average positive profit lagged by 4 months $(M H U F)$ & $\bar{\pi}_{i, m-4}^{+}$ \\
Monthly average negative profit lagged by 1 month $(M H U F)$ & $\bar{\pi}_{i, m-1}^{-}$ \\
Monthly average negative profit lagged by 2 months $(M H U F)$ & $\bar{\pi}_{i, m-2}^{-}$ \\
Monthly average negative profit lagged by 3 months $(M H U F)$ & $\bar{\pi}_{i, m-3}^{-}$ \\
Monthly average negative profit lagged by 4 months $(M H U F)$ & $\bar{\pi}_{i, m-4}^{-}$ \\
December & $\mathrm{DEC}^{-}$ \\
Year 2009 & $\mathrm{YEAR}_{2009}$ \\
Year 2010 & $\mathrm{YEAR}_{2010}$ \\
Year 2012 & $\mathrm{YEAR}_{2011}$ \\
\hline
\end{tabular}


The dependent variable is the monthly average exposure, and the explanatory variables are the profits of the last 4 months and the previous month's exposure in Model 1. Model 2 extends this model by involving the December-effect and year dummies.

In the next specifications, positive and negative profits are differentiated:

$$
\bar{X}_{i, m}=\alpha_{i}+\sum_{k=1}^{4} \beta_{k}^{+} \bar{\pi}_{i, m-k}^{+}+\sum_{k=1}^{4} \beta_{k}^{-} \bar{\pi}_{i, m-k}^{-}+\delta \bar{X}_{i, m-1}+\theta \mathrm{DEC}+\sum_{l=2009}^{2012} \tau_{l} \mathrm{YEAR}_{l}+\varepsilon_{i, m} .
$$

Models 3 and 4 involve positive profits and negative profits separately; while Model 5 contains both positive and negative profits as explanatory variables. We run panel regressions with cluster-robust standard error to account for heteroscedasticity and correlation in the error term within the clients. Table 3 shows the regression coefficients and their $p$-values. (In Table 3, we present results only with net exposures, gross exposures give similar results.)

Remark A positive coefficient means increasing risk-taking as a function of previous profits in the ranges of both positive and negative profits. Note that profits are signed numbers. The benchmark year is 2008 .

The exposure of the previous month is significant in all the specifications; the only other significant variable is the profit lagged by 2 months in Models 1 and 2, and the negative profit lagged by 2 and 3 months in Models 4 and 5. We can see from Fig. 2 that most of the transactions have a maturity of 1-2 months, so it can last several months for the clients to effectuate their trading strategy.

Most importantly, the signs of the coefficients of previous profits are positive both in the regions of negative and positive profits (where these are significant), which is consistent with a CRRA utility function. Behavioral effects could be detected only if profit coefficients were of different sign in different regions. We can conclude, therefore, that we find no signs of irrational risk-taking at this level of aggregation, which can be due to the rational behavior of most of the professional traders in the sample, at least on a monthly time scale. In the following, we investigate the client-level data to identify clients with potential irrational behavior.

\section{Client-level behavioral patterns}

For a more detailed, client-level analysis, we return to a daily time scale and specify two separate linear regression models for each client to explain their daily exposure, one for the region of negative and one for the region of positive profits:

$$
\begin{gathered}
X_{i, t}=\alpha_{i}^{-}+\beta_{i}^{-} \tilde{\pi}_{i, t-1}^{-}+\delta_{i}^{-} \tilde{X}_{i, t-1}+\varepsilon_{i, t}, \\
X_{i, t}=\alpha_{i}^{+}+\beta_{i}^{+} \tilde{\pi}_{i, t-1}^{+}+\delta_{i}^{+} \tilde{X}_{i, t-1}+\varepsilon_{i, t},
\end{gathered}
$$




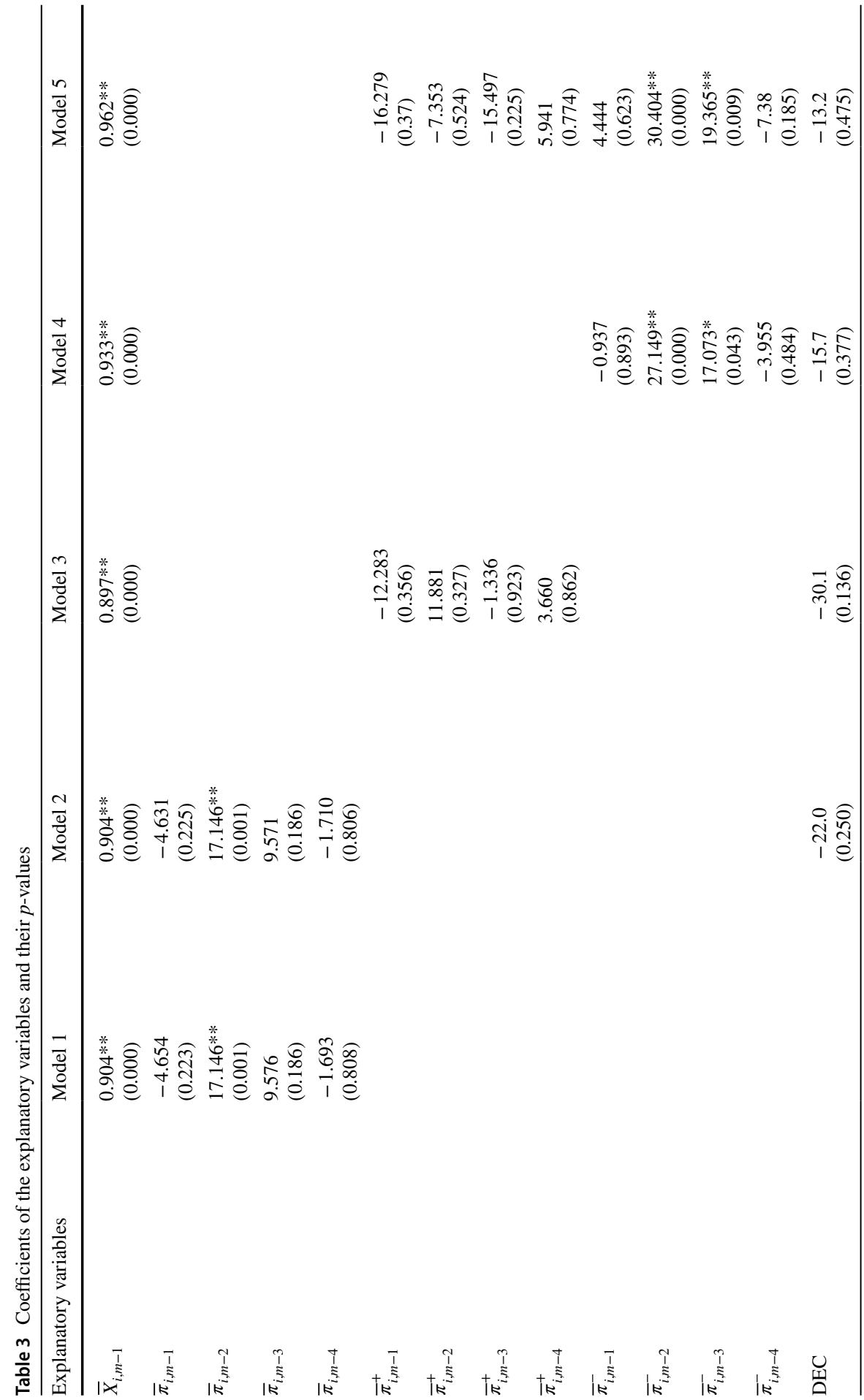

站 


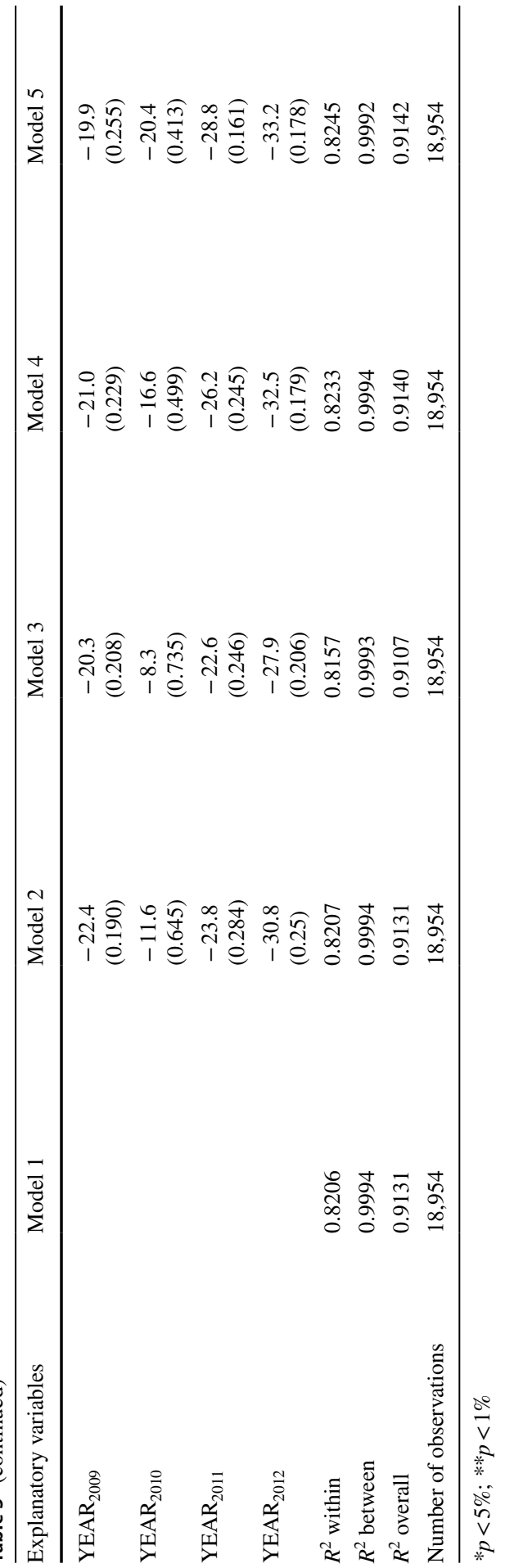


where $\tilde{\pi}_{i, t-1}^{-}$and $\tilde{\pi}_{i, t-1}^{+}$are client-specific previous negative and positive profits, respectively, and $\tilde{X}_{i, t-1}^{i, t-1}$ is the average size of previous exposures of the client. Note, however, that previous profits and exposures are modelled slightly differently here $\left(\tilde{\pi}_{i, t-1}, \tilde{X}_{i, t-1}\right)$ than in the panel regression models $\left(\bar{\pi}_{i, m-1}, \bar{X}_{i, m-1}\right)$. There, the time scale was 1 month and only the last 4 months' profits and the last month's exposure was considered as potential explanatory variables. Here, we switch to a daily time scale and the weighted average of profits and exposures of the whole last year are calculated to account for yearly cycles and for the recency effect.

As we are looking for longer term behavioral effects, we take all profits in the last year into account but conferring more weights to more recent experiences:

$$
\tilde{\pi}_{i, t}=\sum_{k} W_{k} \cdot \pi_{i, k}
$$

Assuming 250 trading days per year, we use an exponential weighting function:

$$
W_{k}=\frac{1}{A} \cdot \mathrm{e}^{-\frac{k}{250} \ln \left(\frac{1}{250}\right)},
$$

where $W_{k}$ stands for the weight of the $k$ th observation, $k=1$ is the oldest and $k=250$ is the most recent one, and

$$
A=\sum_{i=1}^{250} \mathrm{e}^{-\frac{i}{250} \cdot \ln \left(\frac{1}{250}\right)} .
$$

In this setting, the ratio between the largest and the smallest weight is around 245 , meaning that the profit of yesterday is 245 times more important than that of a year ago. The last day's weight is about $2.2 \%$ and the weight of the last 4 months is more than $85 \%$.

The average exposures of the last year $\tilde{X}_{i, t-1}$ is a control variable representing the actual hedging need. Just like in the case of previous profits, we use exponential weights:

$$
\tilde{X}_{i, t-1}=\sum_{k} W_{k} \cdot X_{i, k}
$$

To detect client-level behavioral patterns, we estimate the coefficients of (9) and (10) for the trading data of the clients with the help of OLS regression. We allow clients to have different decision rules for previous negative and positive profits. To this end, we separate the samples of each client into two categories: one where $\tilde{\pi}_{i, t}$ was negative, and another one where it was non-negative, see Fig. 3 showing the relationship between previous profits and present risk exposure of two selected clients.

Naturally, the lengths of the data series for different clients are not the same. Some have open positions for the entire observation period, while others only for a very short time. Additionally, in some cases, these short series of open positions 

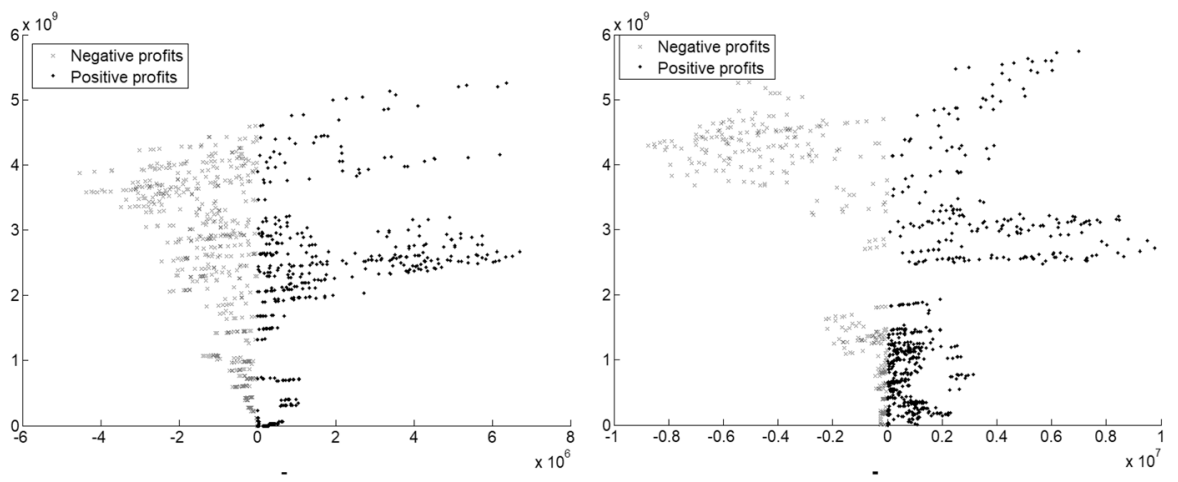

Fig. 3 Risk exposure as a function of previous profits for two selected clients

occur during the first year of the observation period which are lost for the regression analysis, because of the exponentially weighted variables.

Coefficients in (9) and (10) are estimated first for the net exposure (1) and second for the gross exposure (2). Similarly to the aggregate model, results here are similar for net and gross exposure, so we present the results only for the net exposure $\left(X_{i, t}^{\text {net }}\right)$. The primary focus of our attention is on the significance and the sign of the coefficients of previous profits, $\beta_{i}^{-}$and $\beta_{i}^{+}$.

We consider a coefficient significant if it is significant at $95 \%$, and the $\varepsilon$ error term of the equation does not have a unit root according to the ADF (Augmented Dicky Fuller) test with $95 \%$ significance. There are three different cases for each coefficient:

- significant with positive sign (/)

- significant with negative sign (\)

- not significant, so the sign does not matter (-)

Considering both negative and positive profits, a client's behavior may have nine patterns. If coefficients are significant in both regressions, then the exposure as a function of the previous profits (see Fig. 3) may be:

- increasing for negative profits, increasing for positive profits (//-shape)

- increasing for negative profits, decreasing for positive profits $(\Lambda$-shape $)$

- decreasing for negative profits, increasing for positive profits ( $\mathrm{V}$-shape)

- decreasing for negative profits, decreasing for positive profits (II-shape)

There are four other patterns where one of the coefficients is not significant, and it is also possible that neither of the coefficients are significant. Table 4 summarizes all the nine behavioral patterns and their frequency in our data sample.

Monotone increasing behavioral patterns (1, 5, and 7) can be explained by rational decision making supposing for example a CRRA (constant relative risk aversion) utility function, or by the irrational Minsky-effect. Monotone decreasing 
Table 4 Behavioral patterns of the clients

\begin{tabular}{|c|c|c|c|c|c|c|}
\hline \# & Behavioral patterns & & $\begin{array}{l}\text { Number } \\
\text { of clients }\end{array}$ & Percentage & $\begin{array}{l}\text { Average number of } \\
\text { transactions per client }\end{array}$ & $\begin{array}{l}\text { Average daily } \\
\text { net exposure (M } \\
\text { HUF) }\end{array}$ \\
\hline 1 & pos_pos & l, I & 2 & 1.2 & 312 & 1030 \\
\hline 2 & pos_neg & $/, 1$ & 0 & 0.0 & $\mathrm{n} / \mathrm{a}$ & $\mathrm{n} / \mathrm{a}$ \\
\hline 3 & neg_pos & $1, /$ & 18 & 10.8 & 618 & 1850 \\
\hline 4 & neg_neg & 1,1 & 6 & 3.6 & 690 & 5750 \\
\hline 5 & pos_not & $/,-$ & 1 & 0.6 & 409 & 2240 \\
\hline 6 & neg_not & $\backslash,-$ & 32 & 19.3 & 462 & 2600 \\
\hline 7 & not_pos &,$- /$ & 16 & 9.6 & 459 & 3170 \\
\hline 8 & not_neg &,- 1 & 11 & 6.6 & 543 & 2990 \\
\hline \multirow[t]{2}{*}{9} & not_not &,-- & 80 & 48.2 & 206 & 1770 \\
\hline & Overall & & 166 & 100.0 & & \\
\hline
\end{tabular}

behavioral patterns $(4,6$, and 8$)$ can be explained rationally by a special utility function or by the manipulation of the performance measures. Non-monotone behavioral patterns (2 and 3), however, cannot be explained rationally (supposing a stable wealth utility function), these would reflect irrational behavioral effects. Most of all, the V-shape pattern (3) is consistent with the findings of Post et al. (2008) which can be explained by the break-even effect (for negative profits) and the house-money effect (for positive profits) or by the confirmation bias to some extent.

Our research design is different from that of Post et al. (2008) in many aspects (long term versus intraday behavioral effects, professional versus non-professional decision makers, continuous versus discrete variables of profits and exposures), but we got very similar results in the sense that V-shape seems to be the dominant pattern (at least when we have any pattern) even if it is much less accentuated in our sample.

We can see in Table 4 that only $26(15.7 \%)$ of the clients show significant patterns both for negative and positive profits. 18 of them (69\%) exhibit a V-shape behavioral pattern which amounts to the $10.8 \%$ of the total number of clients included in the examination. Clients with pattern 3 tend to transact more frequently than the others but the average size of their open positions is relatively low.

Although we have a total of 351 clients in our sample, the number of clients displayed in Table 4 is 166 . This is because we present only those clients that had enough transactions to perform all the tests for both negative and positive profits (at least 10 observations are needed to perform the test in our setting). So, we excluded 185 clients for the scarcity of data. Moreover, some of the remaining clients are excessively asymmetric in their profitability, meaning that they are either winning or losing most of the time and therefore, they have only few observations on the opposite side.

Note that patterns 6 and 7 may represent one half (left or right) of the V-shape, with no significant coefficient on the other side. These cases comprised 32 and 16 clients, respectively, which add up to $19.3 \%$ and $9.6 \%$ of the total number of clients. 
Table 5 Major behavioral patterns

\begin{tabular}{llll}
\hline$\#$ & Behavioral patterns & $\begin{array}{l}\text { Number of } \\
\text { clients }\end{array}$ & Percentage \\
\hline a & V-shape & 18 & 10.8 \\
b & Half V-shape & 48 & 28.9 \\
c & Other significant cases & 20 & 12.0 \\
d & Nothing is significant & 80 & 48.2 \\
& Overall & 166 & 100.0 \\
\hline
\end{tabular}

Focusing on this V-shape, Table 5 presents the same findings in a compressed form. It shows that significant cases consistent with $\mathrm{V}$-shape altogether amount to $10.8 \%+28.9 \%=39.7 \%$ of the clients, while all the non-related significant cases add up to $12.0 \%$. The remaining $48.2 \%$ of the clients do not exhibit significant coefficients on either side.

We can conclude that a considerable percentage (51.8\%) of the clients in our sample (consciously or unconsciously) consider previous profits when deciding about their risk exposure. The V-shape pattern (10.8\% of the clients) cannot be explained on a rational basis and it corresponds to the findings of Post et al. (2008), but here, with longer horizon and professional decision makers, it is less accentuated.

Of course, banks have more information, so they can investigate their clients' behavior in more detail and develop more sophisticated models. In any case, those clients showing signs of irrational risk-taking should be monitored more carefully.

\section{Conclusions}

We investigate the risk-taking behavior of professional clients and find no behavioral patterns at an aggregate level. However, at a client level, 51.8\% of the observed clients (having enough transactions to derive conclusions in statistical terms) show some significant relationship between previous profits and subsequent risk exposure. If there is a significant relationship, then the most representative pattern is $\mathrm{V}$-shaped or half V-shaped. Therefore, $39.7 \%$ of the observed clients tend to increase (decrease) their exposures after profits of large (small) absolute value. A V-shape pattern cannot be explained by rational decision making and can be a sign of behavioral effects such as break-even and house-money effects similarly to the findings of Post et al. (2008).

As irrational behavioral effects destroy value both at individual and social levels, investors and regulators should pay attention to these symptoms. Our research has some obvious limitations as we had no information about clients' actual hedging need, their trading activities with other banks, the identity of their traders; and we had no mark-to-market forward prices when estimating profits. However, if this additional information is available, the methodology presented in this paper can be improved and used to detect market players exhibiting irrational behavior more effectively. 
Acknowledgements This research was supported by the Higher Education Institutional Excellence Program of the Ministry for Innovation and Technology in the framework of the „Financial and Public Services" Research Project (Reference Number NKFIH-1163-10/2019) at Corvinus University of Budapest. The authors are grateful for ING Bank N. V. for the database.

Funding Open access funding provided by Corvinus University of Budapest.

\section{Declarations}

Conflict of interest On behalf of all authors, the corresponding author states that there is no conflict of interest.

Open Access This article is licensed under a Creative Commons Attribution 4.0 International License, which permits use, sharing, adaptation, distribution and reproduction in any medium or format, as long as you give appropriate credit to the original author(s) and the source, provide a link to the Creative Commons licence, and indicate if changes were made. The images or other third party material in this article are included in the article's Creative Commons licence, unless indicated otherwise in a credit line to the material. If material is not included in the article's Creative Commons licence and your intended use is not permitted by statutory regulation or exceeds the permitted use, you will need to obtain permission directly from the copyright holder. To view a copy of this licence, visit http://creativecommons.org/licen ses/by/4.0/.

\section{References}

Arrow, K.J. 1965. Aspects of the Theory of Risk-Bearing. Helsinki: Yrjö Jahnssonin Säätiö. Benchimol, J. 2014. Risk aversion in the Eurozone. Research in Economics 68 (1): 39-56.

Brown, G., P. Crabb, and D. Haushalter. 2006. Are firms successful at selective hedging? The Journal of Business 79: 2925-2950.

Cohn, A., J. Engelmann, E. Fehr, and M.A. Maréchal. 2015. Evidence for countercyclical risk aversion: An experiment with financial professionals. American Economic Review 105 (2): 860-885.

Coval, J.D., and T. Shumway. 2005. Do behavioral biases affect prices? The Journal of Finance 60 (1): $1-34$.

Faulkender, M. 2005. Hedging or market timing? Selecting the interest rate exposure of corporate debt. Journal of Finance 60: 931-962.

Herings, P.J.J., and F. Kubler. 2007. Approximate CAPM when preferences are CRRA. Computational Economics 29: 13-31.

Goetzmann, W., J. Ingersoll, M. Spiegel, and I. Welch. 2007. Portfolio performance manipulation and manipulation-proof performance measures. Review of Financial Studies 20 (5): 1503-1546.

Guiso, L., P. Sapienza, and L. Zingales. 2018. Time varying risk aversion. Journal of Financial Economics 128 (3): 403-421.

Lakonishok, J., A. Shleifer, R. Thaler, and R. Vishny. 1991. Window dressing by pension fund managers. The American Economic Review 81 (2): 227-231.

Mehra, R., and E.C. Prescott. 1985. The equity premium, a puzzle. Journal of Monetary Economics 15: $145-161$.

Mengel, F., E. Tsakas, and A. Vostroknutov. 2016. Past experience of uncertainty affects risk aversion. Experimental Economics 19: 151-176.

Minsky, H.P. 1986. Stabilizing an unstable economy. New Haven: Yale University Press.

Post, T., M.J. Van den Assem, G. Baltussen, and R.H. Thaler. 2008. Deal or no deal? Decision making under risk in a large-payoff game show. The American Economic Review 98 (1): 38-71.

Tversky, A., and D. Kahneman. 1979. Prospect theory: An analysis of decision under risk. Econometrica 47: 507-608.

Tversky, A., and D. Kahneman. 1992. Advances in prospect theory: Cumulative representation of uncertainty. Journal of Risk and Uncertainty 5: 297-323. 
Publisher's Note Springer Nature remains neutral with regard to jurisdictional claims in published maps and institutional affiliations. 